\title{
TWO CASES OF CONGENITAL MITRAL STENOSIS TREATED BY VALVOTOMY \\ BY
}

\author{
B. D. BOWER, J. W. GERRARD, A. L. D'ABREU and C. G. PARSONS \\ From the Children's Hospital, Birmingham
}

(RECEIVED FOR PUBLICATION JANUARY 16, 1953)

Congenital mitral stenosis is rare but its accurate diagnosis is more than an academic exercise since surgical relief may now be possible.

It is usually associated with anomalies of the septa and great vessels and hypoplasia of the left ventricle and aorta, a combination of defects usually attributed to unequal division of the common atrioventricular canal (Rokitansky, 1875, quoted by Brown, 1939; Abbott, 1927). Patent ductus arteriosus, atrial or ventricular septal defects, or coarctation of the aorta may accompany these anomalies. Death usually occurs within the first few days or weeks of life. The necropsy records of the Birmingham Children's Hospital for the years 1940 to 1951 inclusive contain 198 examples of congenital heart disease. Mitral stenosis or atresia which, because of co-existent left ventricular and or aortic hypoplasia was considered to be due to unequal division of the atrio-ventricular canal, was observed on 15 occasions. The patients survived from one hour to two years eight months; 12 died within the first six weeks of life.

Much more rarely, however, mitral stenosis occurs without any other associated anomaly. One possible example was found in this necropsy series, the child living for six months. This type of case is important since successful valvotomy should add many years to the patient's life. We describe two cases, which we believe are the first in which valvotomy has been performed.

\section{Case Reports}

Case 1. This patient, a girl, was aged $5 \frac{1}{2}$ years at operation.

Pregnancy and birth were normal. Shortly after birth she was said to have signs of congenital heart disease. From the age of 9 months to $3 \frac{1}{2}$ years, when she was first seen at this hospital, she had repeated attacks of bronchitis and pneumonia. Her exercise tolerance was moderately impaired but there was no history of cyanosis or squatting. One of her four siblings has a patent ductus arteriosus. There is no history of rheumatic infection in the patient or her family. At the age of $3 \frac{1}{3}$ years she was $10 \mathrm{lb}$. under weight. There was no cyanosis or clubbing. The heart was not enlarged and at the apex there was a widespread diastolic thrill and a long diastolic murmur ending with a crescendo effect in a slapping first sound. The pulmonary second sound was accentuated.

INVESTIGATIONS. Radiographs showed a slightly enlarged heart with some pulmonary congestion. There was no evidence of left ventricular hypoplasia in the left oblique view.

An E.C.G. showed a suggestion of right ventricular preponderance with a broad and abnormal $P$ wave in all leads (Fig. 1).

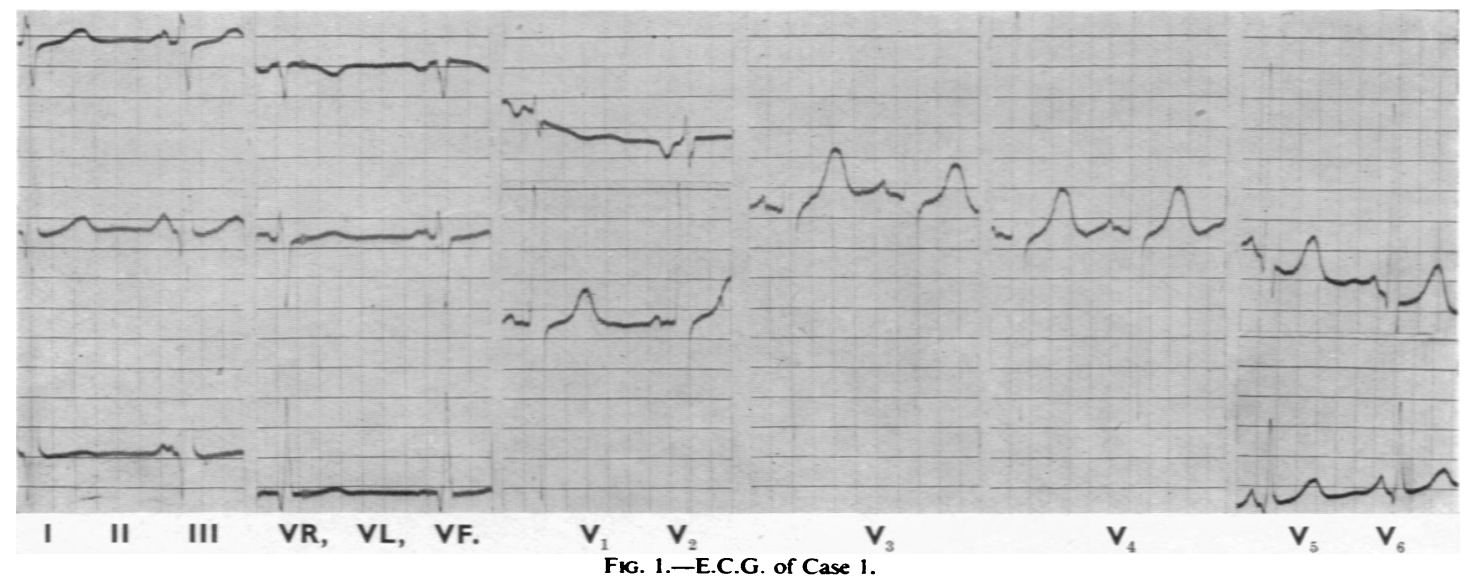




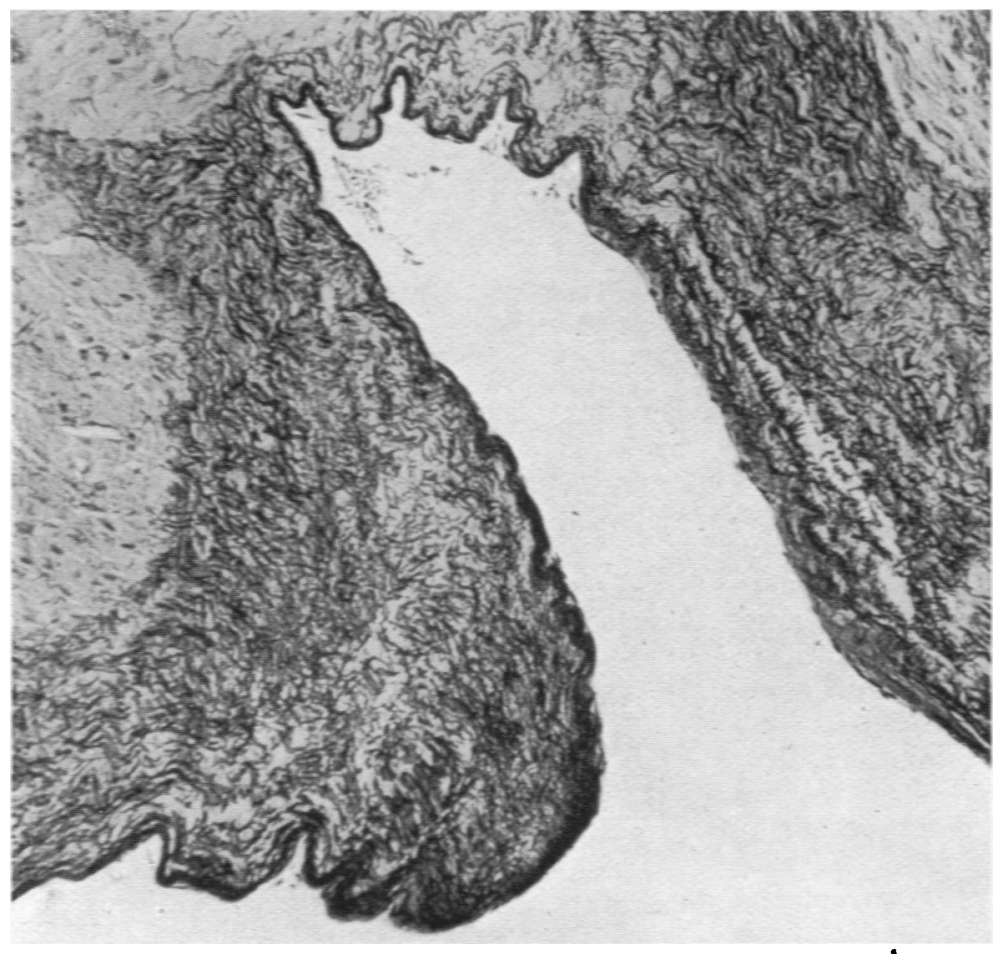

Fig. 2-Section of left auricle showing fibro-elastosis of the endocardium (Weigert elastica, van Gieson $\times 120$ ).

Fig. 3.- Section of lung showing the changes in a branch of the pulmonary artery (Weigert elastica, van Gieson

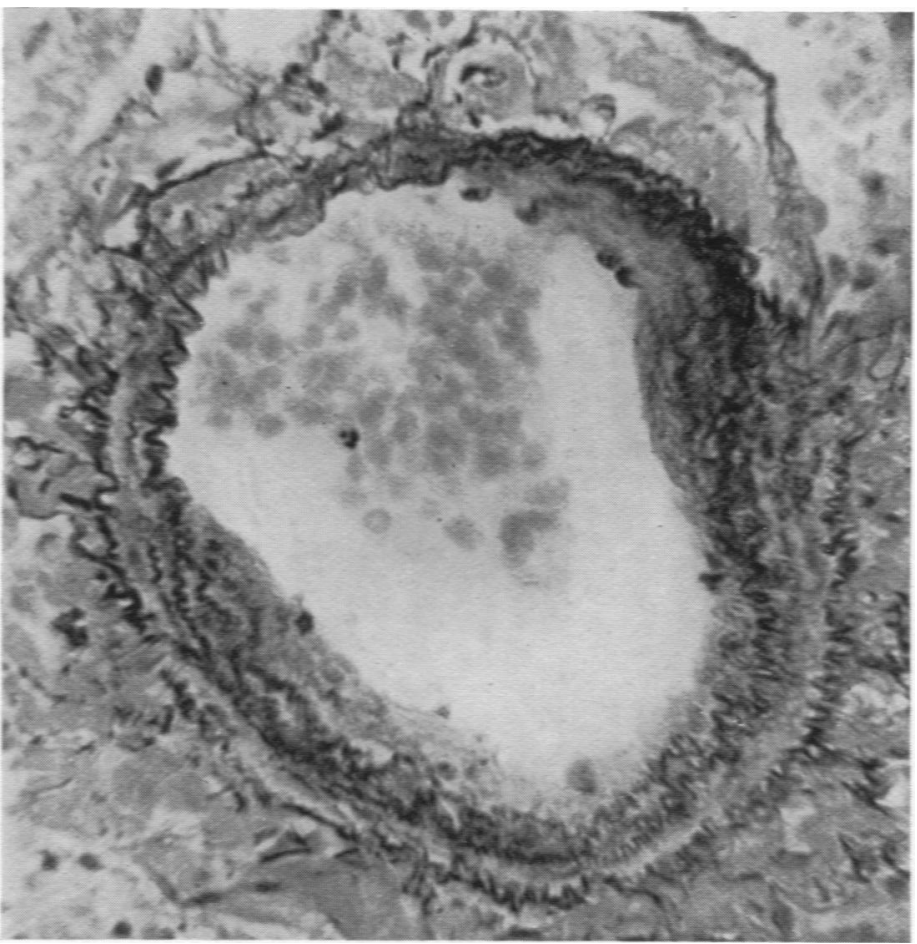
$\times 220$ ). 
Angiocardiography. The diodone entered the descending arch of the aorta from the right ventricle and later in the series the ascending aorta was filled from the left ventricle in the usual manner. The left heart chambers were large. It seemed probable that mitral stenosis might have raised the pulmonary artery pressure suffciently to reverse the flow in a patent ductus arteriosus. (This was confirmed by the fact that after this procedure the feet were more cyanosed than the hands whereas no difference had been observed previously.)

Cardiac catheterization performed seven months later showed the pressure in the right ventricle to be extraordinarily high (i.e. $58 \mathrm{~cm}$. of water above the table top) as it was in the pulmonary artery, and there was increased oxygen saturation in the pulmonary artery. These findings supported the diagnosis but suggested that the flow in the ductus was now in the usual direction (aorta to pulmonary artery).

As her condition had deteriorated since her first examination at the age of $3 \frac{1}{2}$ years, thoracotomy was performed by one of us (A.L.d'A.). It was argued that if pulmonary artety pressure, as measured by direct insertion of a needle, fell during temporary occlusion of the ductus then the ductus should be interrupted, as the flow must be in the usual direction. If this did not oocur, then the flow must be from pulmonary artery to aorta and mitral valvotomy should be proceeded with as the only way of reducing the pulmonary hypertension. The transient attacks of cyanosis were accepted as evidence that periodic reversal of blood flow through the ductus did occur.

OPeration. This was performed on January 17, 1952.

The anaesthetic used was pentothal, curare, and oxygen delivered through an intra-tracheal tube. The left chest was opened through the classical posterior lateral thoracotomy, the pleura being opened through the bed of the resected fourth rib. The left lung was grossly plethoric and heavy and the lymphatic nodes of the mediastinum were dark resembling those seen in some adult patients with mitral stenosis associated with haemosiderosis of the lung. The ductus arteriosus was exposed in the usual way. It was very large and clearly formed a big channel between the aorta and the pulmonary artery. There was no thrill palpable and this in itself was regarded as an indication of reversal of flow through a wide channel. After the ductus had been fully exposed a needle was inserted into its lumen and a pressure of over $145 \mathrm{~cm}$. of saline recorded on the manometer. With the needle still in place the ductus was temporarily occluded and the pressure, if anything, rose. The reversed flow was obviously acting as a protective mechanism and ligation of the ductus was contra-indicated. The pericardium in front of the left phrenic nerve was opened widely. The auricular appendage of the left atrium was distended and, in spite of the age of the child, was readily occluded by Brock's clamp. An incision was made in the appendage sufficiently large to admit the index finger. The clamp was opened and the mitral valve explored digitally. The valve orifice was the size of a pencil and no commissures could be felt. The whole valve area was firm and in no way resembled that encountered in adult mitral stenosis. With considerable difficulty the valve was split and the index finger could then enter the left ventricle comparatively easily. The auricular wound was closed with interrupted fine thread sutures and the clamp removed. The pericardium was loosely closed and the thoracic wound closed with interrupted thread sutures without drainage.

The child stood the operative intervention very satisfactorily and left the table with a blood pressure the same as that recorded before the operation.

At operation a biopsy was done of the left lung and the left atrium.

Biopsy Examinations. The following are recorded.

Left Atrium. There was marked infiltration of subepicardial connective tissue with lymphocytes, polymorphonuclear leucocytes and plasma cells, which extended into the interstitial tissue of the outer part of the myocardium. The endocardium was very thick due to numerous layers of elastic fibres and less numerous collagenous fibres (Fig. 2).

Lung. There was partial collapse, and heart failure cells were present in the alveoli. There was oedema and moderate mononuclear infiltration of the interalveolar septa. Myoelastic hypertrophy of the small branches of the pulmonary artery was present, with cushion-like proliferation of the subendothelial intimal tissue (Fig. 3).

Follow-UP. Seven months after operation her exercise tolerance has greatly increased. Her cardiac signs have varied. At times a rough presystolic murmur with a slapping first sound has been present, and at other times there have been a murmur and thrill occupying the whole of diastole. A ductus murmur has been heard occasionally. Her feet are sometimes a little more cyanotic than the hands showing that at times the pulmonary artery pressure exceds the aortic.

Cardiac catheterization four months after operation showed a pulmonary artery pressure of $128 \mathrm{~cm}$. of saline above the table top and an oxygen saturation greater in the pulmonary artery than in the right ventricle. There was, therefore, still gross pulmonary hypertension, and the shunt on that occasion seemed to be from the aorta to the pulmonary artery.

Case 2. This was a boy aged $9 \frac{1}{2}$ months at operation. Pregnancy and birth were normal (birth weight $5 \mathrm{lb}$. 1 oz.). He was admitted to the Children's Hospital, Birmingham, on February 14, 1952, aged 7 months. For the previous six weeks he had not taken his feeds, had failed to gain weight, and had had a slight cough. He was a pale, somewhat wasted, fretful baby, weighing $10 \mathrm{lb} .8 \mathrm{oz}$., but he was not cyanosed or dyspnoeic. The heart was enlarged and a presystolic thrill and rough crescendo murmur followed by a soft systolic murmur were heard. The heart sounds seemed normal, but on later occasions the mitral first sound was slapping in character. The liver and spleen were enlarged and there were inspiratory crepitations at the base of the left lung.

He became dyspnoeic after admission and his respiratory rate rose. Accordingly 'digoxin' was started on the fifth day, with initial improvement. A week later, however, he again deteriorated and showed signs of left- and right-sided cardiac failure. Aminophylline, mersalyl, 
and 'papaveretum' were given in addition to the 'digoxin' and he again improved within the next 24 hours. For the next two weeks he remained in mild respiratory distress

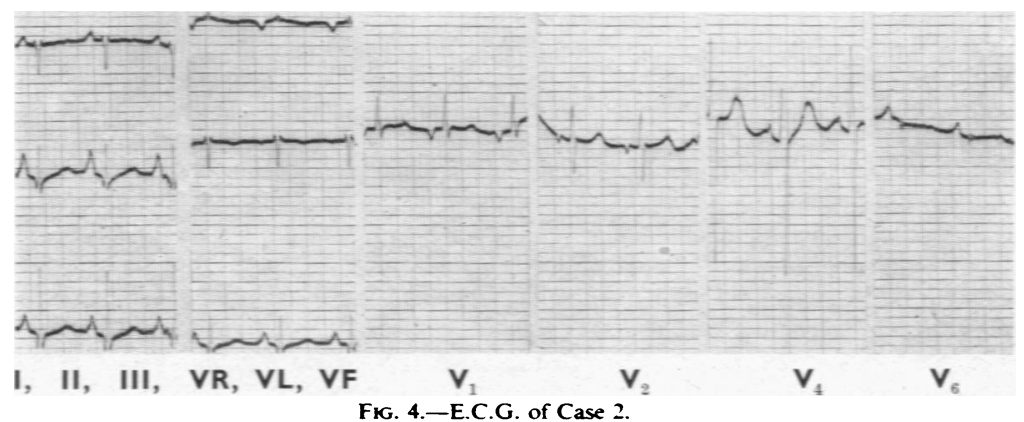

Operation (A.L.d'A.). On May 1 under pentothal, curare and intra-tracheal oxygen anaesthesia, the left chest was widely opened through the bed of the resected fifth rib. The pericardial sac, which contained an excessive amount of fluid, was opened in front of the left phrenic nerve. The left atrium and its appendage were grossly distended. The right ventricle was greatly dilated and appeared to be almost aneurysmal towards its apex. The left pulmonary artery was enlarged and the aorta smaller than usual though by no means hypoplastic. The pressure in the pulmonary artery was recorded by means of a saline manometer and was over $85 \mathrm{~cm}$. of saline. The left

but without clinical evidence of cardiac failure, and it was possible to perform angiocardiography and cardiac catheterization during this time. He then had a second attack of cardiac failure despite continued treatment.

INVESTIGATIONS. A radiograph on admission showed an enlarged heart with vascular engorgement of both lung fields spreading out from the hila, more marked on the right.

An E.C.G. showed right ventricular preponderance and an abnormal $P$ wave in all leads (Fig. 4).

Cardiac Catheterization. There appeared to be either a very large right atrium or else a large atrial septal defect because of the distance through which the catheter tip could be moved transversely, but the oxygen contents of the samples of blood obtained with the catheter tip at the two limits of its excursion were the same. The abnormality was therefore assumed to be a large right atrium.

\begin{tabular}{l|c}
\hline Site & $0_{2}$ Content (vol. \%) \\
\hline $\begin{array}{l}\text { Inferior vena cava } \\
\text { Right atrium }\end{array}$ & (R) $8 \cdot 89.9$ \\
Right ventrick & $\cdots$
\end{tabular}

There was thus no evidence of a left-to-right shunt.

Angiocardiography. This showed a normal circulatory route, but there was a remarkable hold-up of diodone in the left atrium. This chamber appeared rather large, and the left ventricle was not seen adequately filled in any of the pictures (Fig. 5).

As these findings supported the diagnosis and, as he had had two attacks of failure while fully digitalized, it was decided that mitral valvotomy should be attempted.
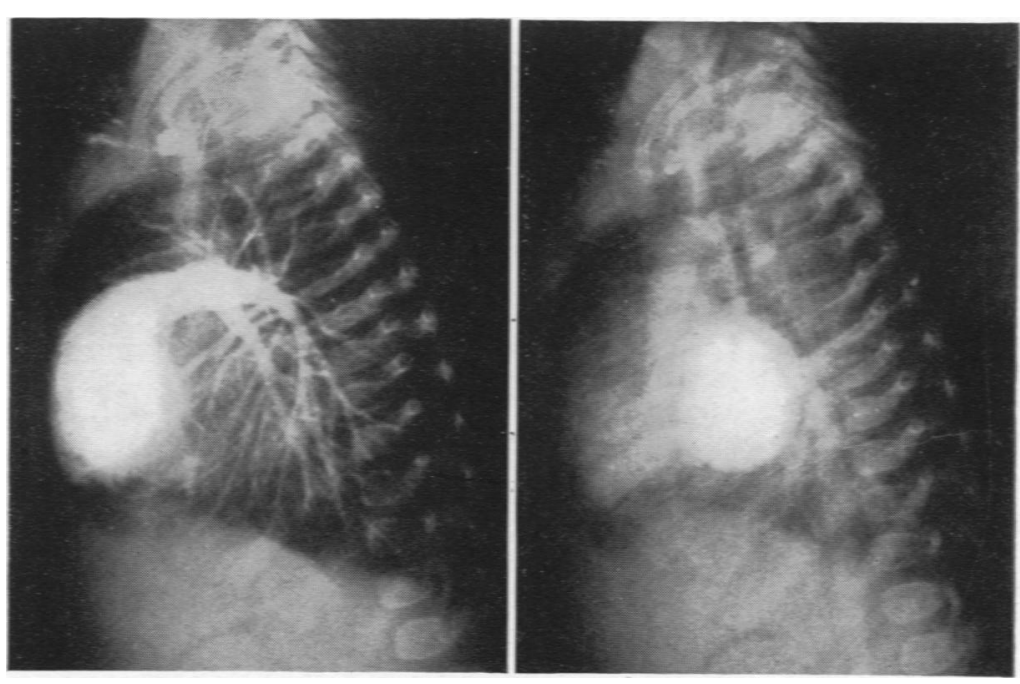

FK. 5.-Angiocardiogram: (a) 1.7 seconds, showing filling of the right ventricle and branches of the pulmonary artery: (b) $7 \cdot 1$ seconds showing filling of the dilated left auricle and the whole of the aorta and common iliac arteries. but no dye in the left ventricle. 
The child's immediate post-operative condition was very satisfactory; the colour remained good. The infant remained in good condition for 36 hours but during a feed, choked, collapsed suddenly and died. to patches of chondroid conrective tissue. There were no increase in elastic fibres and no inflammatory changes. The endocardium of the right ventricle was normal, but that of the left ventricle showed patchy thickening

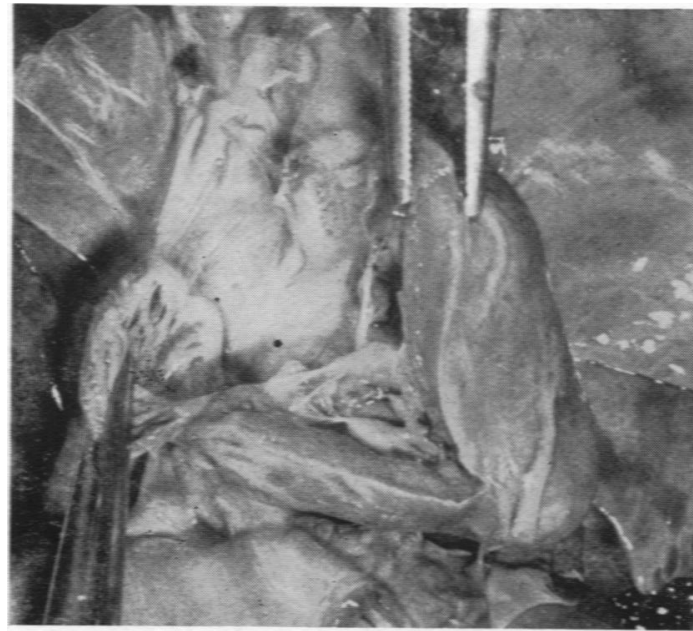

Fig. 6.

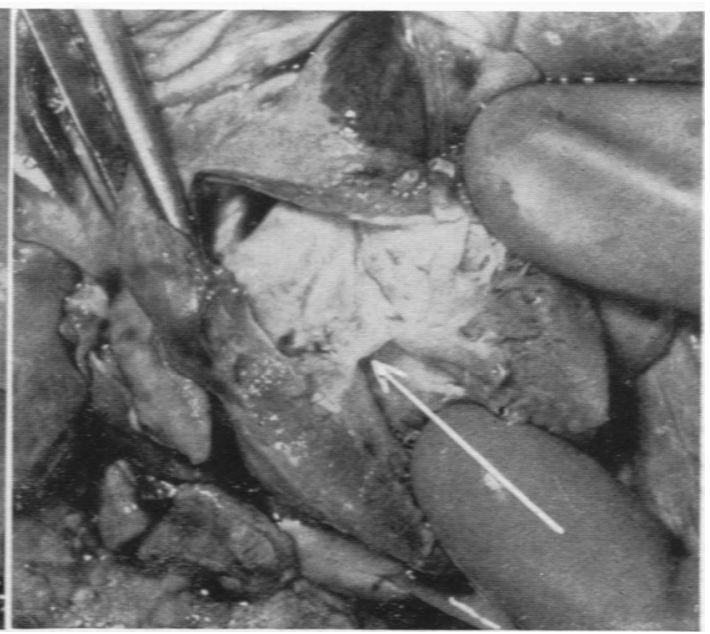

FrG. 7.

Figs. 6 and 7.-Left auricle and left ventricle opened to show the mitral stenosis (free edge of mitral valve arrowed in Fig. 7 ) and the fibro-elastosis of the left auricle.

NeCROPSY (Dr. H. S. Baar). There were no abnormalities outside the cardiovascular and respiratory systems.

The heart was markedly enlarged (weight $56 \mathrm{~g}$.; normal for age, 38 g.). There was eccentric hypertrophy of the right ventricle but the left ventricle was normal in size and its wall was of normal thickness. The maximum thickness of the walls of both ventricles was $7 \mathrm{~mm}$. The cusps of the mitral valve were fused, the aperture only admitting a thin pencil (approximately $5 \mathrm{~mm}$. in diameter). In one place, in the middle of the posterior part of the valve, there was a recent incision $3 \mathrm{~mm}$. in length. The valve itself was thick, hard, nodular and white. There was marked endocardial fibro-elastosis affecting the whole of the left atrium, the cranial part of the left ventricle and, to a lesser degree, the right atrium (mainly on the inter-atrial septum). The tricuspid, pulmonary and aortic valves were normal and the origins of the coronary arteries were normally situated. The position and size of the great vessels were normal and there was no patency of the septa. There were sutures in the wall of the left auricle (Figs. 6 and 7).

There were extensive areas of atelectasis in the lungs, particularly in the left lower lobe. There were also increased marking of the interstitial tissuejand some areas suggestive of carnification.

The mediastinal lymph nodes were enlarged, those at the tracheal bifurcation being about $1 \mathrm{~cm}$. in diameter. They were soft and greyish-red.

Histology. The thickening of the mitral valve was due due mainly to numerous layers of elastic fibres with a few collagenous fibres between them.

The capillaries of the interalveolar septa were distended and engorged. There was partial collapse. The alveoli and alveolar ducts contained macrophages, many of which, if not all, gave a positive Prussian blue reaction (Fig. 8).

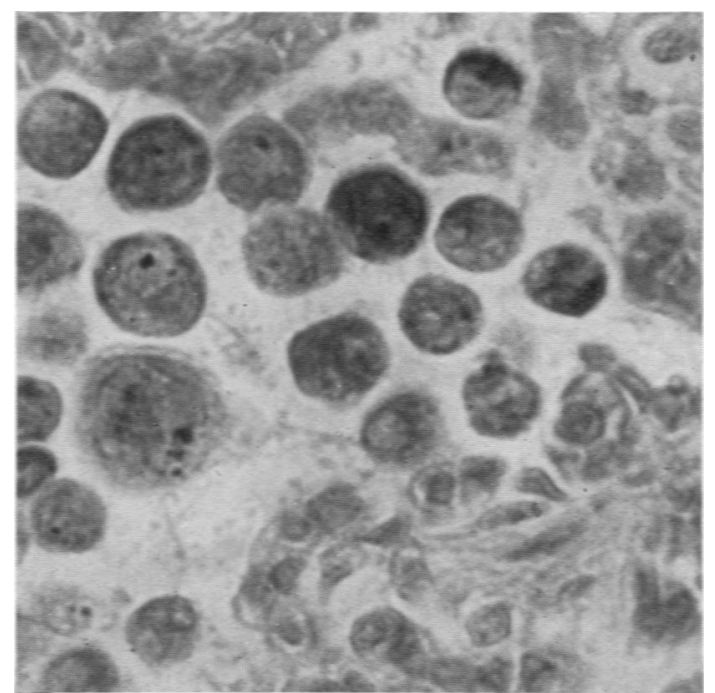

Frg. 8.- Section of lung showing heart failure cells (Prussian blue, $\times$ 480). 
There was moderate myoelastic hypertrophy of the small branches of the pulmonary artery, but no intimal proliferation.

Congestion and centrilobular fatty degeneration of the liver were present.

Case 3. Since these cases were reported a further case of isolated mitral stenosis has come to necropsy at this hospital. Death occurred before the diagnosis could be made, and so valvotomy was not performed. The baby was aged 2 months. The necropsy findings were very similar to those in case 2: fibro-elastosis of the left atrium was present. The mitral valve, although stenosed, showed no evidence of inflammation.

\section{Discussion}

Aetiology. It seems clear that when mitral stenosis is associated with other gross cardiac defects the cause is mal-development of the primitive heart during the first trimester of intra-uterine life (Emery and Illingworth, 1951). Unequal division of the common atrio-ventricular canal is the probable cause. The time when this mal-development occurs, and possibly its extent, determines the degree of mitral stenosis or atresia and the presence or absence of septal defects and abnormalities of the great vessels. 'Atresia' denotes non-development, and 'stenosis' normal development with fusion of the valve cusps, but intermediate stages occur and the terms clearly overlap (Brown, 1939).

When mitral stenosis occurs as an isolated lesion the cause is less certain, and controversy has been acute on this point. The usual cause which was advanced until recent years was foetal endocarditis (Day, 1932; Eigen, 1938; Johnson and Lewes, 1945; McConnell, 1950) and indeed the pathological findings are often similar to those of healed endocarditis. Gross (1941), however, in an exhaustive review of the literature could find no evidence that foetal endocarditis caused any cardiac lesions and gave his own reasons for considering a congenital origin more likely: he pointed out first that in previously reported cases histological examination had not often been performed and that when this had been done the acute stage had never been seen, and secondly that maternal disease had only rarely occurred during pregnancy. The changes usually seen are endocardial fibrosis, extending often as strands into the myocardium; occasionally calcification of the valve; lymphocytes and Aschoff bodies do not occur. He postulated a primary hyperplasia of the endocardial elastic tissue, perhaps causing secondary infarction of the sub-endocardial muscles supplied by arterio-luminal, arterio-sinusoidal and Thebesian vessels. This pathological appearance, now known as fibro-elastosis, has usually been present in the reported cases of mitral stenosis, both with and without other cardiac defects (Day, 1932: Farber and Hubbard, 1933; Johnson and Lewes. 1945; Gross, 1941; Emery and Illingworth, 1951; Blumberg and Lyon, 1952; Johnson, 1952). Some of the authors consider this to be evidence of foetal endocarditis. It certainly occurred in one and probably in both of the cases discussed in this paper and also in nine of the 15 cases of mitral stenosis or atresia of the 'unequal division' type mentioned above. We agree with Gross. If an error of development is indeed the cause in the latter type of case, then 'pure' mitral stenosis is also probably due to this. since fibro-elastosis is common to both. As in most reported cases there were no Aschoff bodies or other evidence of acute rheumatism in the two cases reported here. It is difficult for two other reasons to explain our case 2 on the theory of endocarditis. There is no history of a rheumatic episode in mother or child and, even if a silent rheumatic affection in the mother is assumed, acquired mitral stenosis could not have developed in that time, if the usual minimum time of two or three years is accepted.

Johnson (1952) also rejects foetal endocarditis as a cause of mitral stenosis and fibro-elastosis and postulates anoxia of the endocardium due to (1) coronary artery anomalies, (2) premature closure of the foramen ovale, which would prevent oxygenated blood from entering the left auricle and ventricle, or (3) valvular atresias, from which stagnation anoxia would develop. This theory is attractive, as it explains the more frequent occurrence of the condition on the left side of the heart, since the second mechanism would operate only on the left, while the others would operate equally on the two sides. The author even suggests that when there is premature closure of the foramen ovale the resulting thickening of the endocardium may prevent normal growth of the muscle wall and thus explains the occurrence of left ventricular and aortic hypoplasia in some cases. This explanation, however, cannot displace the 'unequal division' theory, for in some cases of mitral stenosis with a hypoplastic left ventricle and aorta, there is no fibro-elastosis.

Diagnosis. The history in both cases was suggestive, i.e. recurrent pulmonary infections, dyspnoea, and in one case congestive heart failure; physical examination confirmed the diagnosis by the discovery of a classical presystolic murmur and accentuated slapping first sound. These signs, however, were variable and there were times when the diagnosis seemed certain on clinical grounds and other times when it was doubtful.

Investigations were not as helpful as might have been hoped. There was no significant direct radiological enlargement of the left auricle. An E.C.G. 
showed right ventricular preponderance, which is usual at this age, but it did also show a broad and abnormal $\mathbf{P}$ wave in both cases. Cardiac catheterization did not help directly but it excluded septal defects, and confirmed the presence of a silent ductus in case 1 , besides showing extreme pulmonary hypertension in both cases. Angiocardiography, which is not usually regarded as of great value in the diagnosis of mitral stenosis, was useful in case 2 by showing a large left atrium with stasis lasting several seconds, and in case 1 by showing the ductus and the direction of its blood flow.

Selection of Cases for Operation. Congenital mitral stenosis is theoretically the ideal type of case for mitral valvotomy, provided the left ventricle and aorta are normally developed, for cardiac embarrassment is due entirely to the mechanical obstruction and the common contra-indications to operation in the acquired form, namely previous myocardial damage and active infection, are absent. It is important, therefore, to differentiate the type of case with 'pure' mitral stenosis from the 'unequal division' type, for only the former is likely to benefit from the operation. The facilitation of blood flow into the left ventricle is pointless if the aorta is not large enough to receive it. We took the presence of a slapping first sound as evidence of a normal left ventricle. Angiocardiography did not show the size of the chamber, but in case 2 a normal aorta was demonstrated. In case 1 neither left ventricle nor aorta could be demonstrated because of the by-pass. In the absence of definite proof of the diagnosis we think thoracotomy is justifiable if there are signs of pulmonary hypertension or a history of attacks of congestive cardiac failure. It is, of course, impossible at present to make any statement about prognosis after valvotomy but it seems fairly certain that death occurs usually before the age of 5 years without surgery. Secondary change in the pulmonary arterial tree may, however, cause pulmonary hypertension to continue, and thus limit improvement. The problem of the length of time which elapses before pulmonary arterial changes make pulmonary hypertension permanent is at present occupying the minds of cardiologists working with cases of acquired mitral stenosis, and is just as important in the congenital type. It was disturbing to see changes $i \rightarrow$ the branches of the pulmonary artery in case 2 at the age of 9 months. Case 1 only improved slowly after operation, and it is far too early to assess its result.

The Surgical Problems. From the necropsy experience quoted it would seem that most children will require surgery before the age of 5 ; it is, however, important to note that the auricular appendage of one child of 5 was sufficiently capacious to allow a digital examination of the stenosed valve to be carried out. This clearly would be impossible in the case of children under the age of 3 or 4 and surgical attempts at commissurotomy would have to be made blindly by passing a valvulotome through a small incision in the auricular appendage; such a method can never be so accurate or precise as that following a digital exploration, but the experience described in case 2 shows that the operation is possible. The division of the stenosed valve by a knife cannot be placed accurately through the antero-lateral and postero-lateral commissures as in adult mitral stenosis, but this may not be so important in congenital stenosis where there is no sign of properly developed cusps and the condition is more akin to that of pulmonary valvular stenosis: the risk of regurgitation following must be accepted and a certain degree of this would be preferable to a tight stenosis. Both these young hearts stood the surgical intervention extremely well.

\section{Summary}

Two cases of congenital mitral stenosis, one with no other abnormality and the other with a coexistent patent ductus arteriosus, are described. The diagnosis was confirmed at operation and, in one case, also at necropsy.

Mitral valvotomy was performed in both cases.

Clinical diagnosis may be easy at times but difficult at others. Confirmation may be difficult.

The selection of suitable cases is important since valvotomy should help the case with a good left ventricle but could not help the commoner case due to unequal division of the common atrio-ventricular canal.

We wish to thank Dr. H. S. Baar for the pathological reports and sections, Dr. R. Astley for the radiological investigations and Mr. J. G. Williamson for the photographs.

\section{REFERENCES}

Abbott, M. E. (1927). In Osler's Modern Medicine, 3rd ed., vol. IV, p. 754. London.

Blumberg R. W. and Lyon, R. A. (1952). Amer. J. Dis. Child., 84, 291

Brown. J. W. (1939). Congenital Heart Disease. London.

Day, H. B. (1932). Lancet, 1. 1144.

Eigen, L. A. (1938). Amer. Heart J., 16. 363.

Emery, J. L. and Illingworth, R. S. (1951). Archives of Disease in Childhood, 26. 304

Farber, S. and Hubbard, J. (1933). Amer. J. med. Sci., 186. 705.

Gross, P. (1941). Arch. Path., Chicago, 31, 163.

Gross, P. (1941). Arch. Path., Chicago,

Johnson, F. R. (1952). Ibid , 54. 237 . Bend Lewes, D. (1945) Brit. Heart J.. 7.52.

McConnell, B. E. (1950). Archives of Disease in Childhood, 25. 186. 